J. Reprod. Fert. (1967) 14, 203-211

\title{
PHOSPHOLIPIDS OF BOVINE SPERMATOZOA AND SEMINAL PLASMA*
}

\author{
V. G. PURSEL $\dagger$ AND E. F. GRAHAM \\ Department of Animal Science, University of Minnesota, \\ St Paul, Minnesota, U.S.A.
}

(Received 27th May 1966, revised 20th February 1967)

\begin{abstract}
Summary. Spermatozoal and seminal plasma lipids of fourteen individual bulls were separated by column chromatography into neutral lipid and several phospholipid fractions. Elution progress was monitored by thin-layer chromatography. Each phospholipid constituent was determined by phosphorus analysis. Total lipid, cholesterol and plasmalogen contents were determined. The fatty acids and aldehydes of the choline and ethanolamine phosphatide fractions were analysed by gasliquid chromatography.

The spermatozoal phospholipid comprised $35.6 \%$ phosphatidyl choline, 28\% phosphatidal choline, 20\% phosphatidyl ethanolamine, $7 \cdot 2 \%$ phosphatidal ethanolamine and $9.1 \%$ sphingomyelin.

The seminal plasma phospholipid comprised 30\% phosphatidyl choline, $23.6 \%$ phosphatidal choline, $10.5 \%$ phosphatidyl ethanolamine, $16.3 \%$ phosphatidal ethanolamine, $14.1 \%$ sphingomyelin and $5.4 \%$ polyglycerol phosphatide.

Myristaldehyde and palmitaldehyde were the only aldehydes identified in the choline and ethanolamine phosphatide fractions. Docosahexaenoic acid constituted a large portion of the fatty acids of spermatozoal choline phosphatide.
\end{abstract}

\section{INTRODUGTION}

Even though the lipids of bull spermatozoa have been the object of numerous investigations since the initial lipid extractions of Kölliker (1856), knowledge of the qualitative and quantitative nature of the various lipid constituents remains severely limited.

Lovern, Olley, Hartree \& Mann (1957), Hartree \& Mann (1959) and Gray (1960a, b) have partially succeeded in elucidating the chemical nature of the lipids of ram spermatozoa and drew attention to the presence of a high percentage of plasmalogen in the spermatozoal lipids. Hartree \& Mann (1961) presented evidence that the fatty acid moiety of the plasmalogen may be metabolized.

* Scientific Journal Series Paper No. 5959, Minnesota Agricultural Experiment Station.

$\dagger$ Present address: West Central Experiment Station, University of Minnesota, Morris, Minnesota, U.S.A. 
More recently Komarek, Pickett, Lanz \& Jensen (1964), Komarek, Pickett, Gibson \& Jensen (1965) and Komarek, Pickett, Gibson \& Lanz (1965) separated the lipids of bull, boar and stallion spermatozoa and seminal plasma into five lipid classes and determined the concentration of each class using gravimetric procedures.

The purpose of our study was to investigate the lipids of spermatozoa and seminal plasma from individual bulls and to separate and determine their phospholipid components.

\section{MATERIALS AND METHODS}

\section{Semen processing}

Semen was collected from fourteen mature bulls in routine service at two artificial breeding centres. One to three ejaculates were collected so that the total volume of semen exceeded $10 \mathrm{ml} /$ bull. Sperm cell concentration for each ejaculate was determined by the photolometer technique. After gradual cooling to room temperature semen was centrifuged at 20,000 $\mathrm{g}$ for $15 \mathrm{~min}$, the spermatozoa were washed once with 'sperm Ringer' solution and re-centrifuged. The washed spermatozoa and re-centrifuged seminal plasma were stored in liquid nitrogen until analysed.

\section{Lipid extraction}

Lipids were extracted by boiling with 20 vol. chloroform-methanol $(2: 1$, $\mathrm{v} / \mathrm{v}$ ) for $60 \mathrm{~min}$, followed by purification of the extracts by the procedure of Folch, Lees \& Sloane-Stanley (1957) using distilled water for washing. The phases were allowed to separate overnight in a separatory funnel, and the lower phase removed and dried over anhydrous sodium sulphite.

\section{Column chromatography}

Lipids were fractionated on columns of silicic acid (silicic acid, 100 mesh, suitable for chromatographic analysis by the method of Ramsey and Patterson, Analytical Reagent, Mallinckrodt Chemical Works, St Louis, Mo.) and silicate-silicic acid (80 to 120 mesh). Silicic acid columns, prepared according to Rouser, Bauman, Kritchevsky, Heller \& O'Brien (1961), separated the spermatozoal lipids into the neutral lipid fraction, the ethanolamine phosphatide fraction and the choline phosphatide and sphingomyelin fraction (throughout the text ethanolamine phosphatide and choline phosphatide are used to include both phosphatidal and phosphatidyl ethanolamine and choline, respectively). Seminal plasma lipids were separated on silicic acid columns into fractions containing neutral lipid and polyglycerol phosphatide, ethanolamine phosphatide and cerebroside, and choline phosphatide and sphingomyelin.

Silicate-silicic acid columns, prepared according to Massaro (1962), subfractionated the choline phosphatide from sphingomyelin.

Elution of the columns was performed at $5^{\circ} \mathrm{C}$ to reduce the loss of plasmalogens. All solvents were deoxygenated before use and a nitrogen gas atmosphere was used whenever possible. Elution of the lipid fractions was monitored using the microplate thin-layer chromatographic technique of Peifer (1962). 


\section{Gas-liquid chromatography}

Fatty acids and aldehydes of the choline phosphatide and ethanolamine phosphatide fractions were analysed by gas-liquid chromatography. The phosphatides were subjected to alkaline and acid hydrolysis, and the resulting free fatty acids and aldehydes were methylated using the boron-trifluoride-methanol procedure (Metcalfe \& Schmitz, 1961). The methyl esters were then chromatographed on a Beckman GC-2A apparatus using a $\beta$-cyclodextrin acetate column (Sand \& Schlenk, 1961) maintained at $220^{\circ} \mathrm{C}$ with an argon inlet pressure of $25 \mathrm{lb} / \mathrm{in}^{2}$. The detector cell current was $250 \mathrm{~mA}$. Methyl esters were identified by comparison of their retention times with those of authentic methyl ester standards (Hormel Institute, Austin, Minn.). The relative percentage of each ester was calculated from the area under the curve using triangulation.

\section{Analytical methods}

The total phospholipid fraction and each phospholipid sub-fraction were determined by analysis of lipid phosphorus (Bartlett, 1959). The aldehyde content of the total phospholipid, choline phosphatide and ethanolamine phosphatide fractions was determined by the phenylhydrazine method (Wittenberg, Korey \& Swenson, 1956). Total cholesterol content was determined in isopropanol by the ferric chloride-sulphuric acid reaction (Zlatkis, Zak \& Boyle, 1953) using the Technicon AutoAnalyzer. A Cahn microbalance was utilized in the gravimetric determination for total lipid.

\section{RESULTS}

\section{Spermatozoal lipids}

The average concentrations of the identified lipid components of the spermatozoa are listed in Table 1. Total lipid determinations were made for only four spermatozoal samples because petroleum jelly used to lubricate the artificial vaginae during semen collection contaminated the other ten samples. Analysis of the lubricant by thin-layer chromatography revealed that it was composed entirely of petroleum hydrocarbon; thus, quantitative determination for the other lipid constituents was not prevented.

The choline phosphatides accounted for $63.6 \%$ of the total phospholipid with the ethanolamine phosphatides and sphingomyelin making up 27.2 and $9 \cdot 1 \%$, respectively. The plasmalogens made up $35 \cdot 2 \%$ of the phospholipid with the major component being phosphatidal choline.

Even though the choline phosphatides and sphingomyelin were fractionated on the silicate-silicic acid columns, complete separation of these components was not attained. Considerable tailing of the two components undoubtedly contributed to the variation between bulls for these constituents.

The low recovery of lipid phosphorus from chromatographic procedures (average $87 \%$ ) was due to the use of two columns during chromatography and thin-layer chromatography to monitor the elution.

Analysis of variance revealed no significant differences between breeds of bull for any of the lipid constituents. 
TABLE 1

CONCENTRATIONS OF LIPIDS IN THE SPERMATOZOA FROM FOURTEEN BULLS

\begin{tabular}{|c|c|c|c|c|c|}
\hline \multirow{2}{*}{ Constituent } & \multicolumn{3}{|c|}{ Concentration $/ 10^{9}$ sperm } & \multicolumn{2}{|c|}{$\begin{array}{c}\text { Percentage of total } \\
\text { phospholipid }\end{array}$} \\
\hline & $\bar{X}$ & S.E. & Range & $\overline{\boldsymbol{X}}$ & Range \\
\hline $\begin{array}{l}\text { Total lipid (mg) } \\
\text { Total cholesterol }(\mu \mathrm{g}) \\
\text { Total phospholipid }(\mu \mathrm{g}) \\
\text { Total plasmalogen }(\mu \mathrm{g}) \\
\text { Choline phosphatide }(\mu \mathrm{g}) \\
\text { Phosphatidyl choline }(\mu \mathrm{g}) \\
\text { Phosphatidal choline }(\mu \mathrm{g}) \\
\text { Ethanolamine phosphatide } \\
\quad(\mu \mathrm{g}) \\
\text { Phosphatidyl ethanolamine } \\
(\mu \mathrm{g}) \\
\text { Phosphatidal ethanolamine } \\
\quad(\mu \mathrm{g}) \\
\text { Sphingomyelin }(\mu \mathrm{g})\end{array}$ & $\begin{array}{l}2 \cdot 18^{*} \\
270 \\
1377 \\
485 \\
876 \\
490 \\
386 \\
375 \\
276 \\
99 \\
125\end{array}$ & $\begin{array}{r}0 \cdot 22 \\
20 \cdot 74 \\
63 \cdot 46 \\
24 \cdot 03 \\
38 \cdot 81 \\
23 \cdot 11 \\
20 \cdot 86 \\
25 \cdot 12 \\
22 \cdot 65 \\
7 \cdot 23 \\
10 \cdot 58\end{array}$ & $\begin{array}{l}1 \cdot 64-2 \cdot 66 \\
128-393 \\
921-1791 \\
269-639 \\
584-1138 \\
360-624 \\
224-514 \\
231-553 \\
176-442 \\
45-157 \\
56-210\end{array}$ & $\begin{array}{r}35 \cdot 2 \\
63 \cdot 6 \\
35 \cdot 6 \\
28 \cdot 0 \\
27 \cdot 2 \\
20 \cdot 0 \\
7.2 \\
9 \cdot 1\end{array}$ & $\begin{array}{r}29 \cdot 1-46 \cdot 9 \\
57 \cdot 3-68 \cdot 5 \\
29 \cdot 3-42 \cdot 5 \\
23 \cdot 7-35 \cdot 3 \\
22 \cdot 3-30 \cdot 9 \\
14 \cdot 1-24 \cdot 7 \\
4 \cdot 9-11 \cdot 7 \\
4 \cdot 2-12 \cdot 7\end{array}$ \\
\hline
\end{tabular}

* Total lipid determinations were only made on spermatozoa from four bulls.

\section{Seminal plasma lipids}

The phospholipids of seminal plasma were somewhat different qualitatively from those in spermatozoa. Analysis by thin-layer chromatography indicated the presence of two lipid constituents migrating near the solvent front that were not present in spermatozoal phospholipids (Text-fig. 1). These two

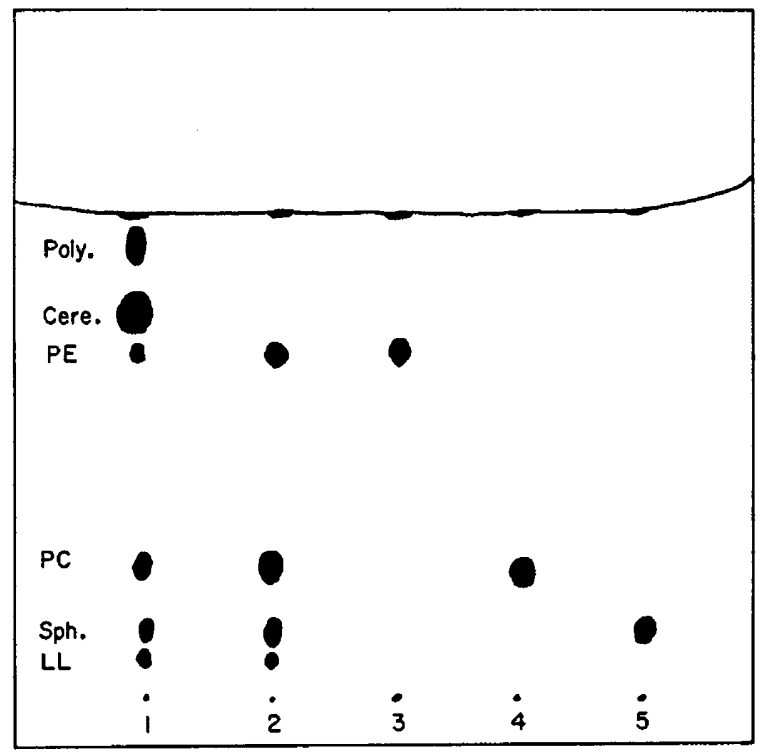

TEXT-FIG. I. Separation of phospholipids on silica gel G. Solvent: chloroform-methanolwater-acetic acid, 45:45:5:5, v/v/v/v. Indicator: $25 \%$ sulphuric acid. Lipids applied: (1) seminal plasma phospholipids, (2) spermatozoal phospholipids, (3) phosphatidyl ethanolamine, (4) phosphatidyl choline, (5) sphingomyelin. Lipids tentatively identified: LL, lysolecithin; Cere., cerebroside; Poly., polyglycerol phosphatide. 
lipid constituents were tentatively identified as polyglycerol phosphatide and cerebroside.

The average concentrations of the various lipid components of the seminal

TABLE 2

CONGENTRATIONS OF LIPIDS IN THE SEMINAL PLASMA FROM FOURTEEN BULLS

\begin{tabular}{|c|c|c|c|c|c|}
\hline \multirow{2}{*}{ Constituent } & \multicolumn{3}{|c|}{ Concentration/ml seminal plasma } & \multicolumn{2}{|c|}{$\begin{array}{c}\text { Percentage of total } \\
\text { phospholipid }\end{array}$} \\
\hline & $\bar{X}$ & $S . E$. & Range & $\bar{X}$ & Range \\
\hline $\begin{array}{l}\text { Total lipid (mg) } \\
\text { Total cholesterol }(\mu \mathrm{g}) \\
\text { Total phospholipid }(\mu \mathrm{g}) \\
\text { Total plasmalogen }(\mu \mathrm{g}) \\
\text { Choline phosphatide }(\mu \mathrm{g}) \\
\text { Phosphatidyl choline }(\mu \mathrm{g}) \\
\text { Phosphatidal choline }(\mu \mathrm{g}) \\
\text { Ethanolamine phosphatide } \\
\text { ( } \mu \mathrm{g}) \\
\text { Phosphatidyl ethanolamine } \\
\text { ( } \mu \mathrm{g}) \\
\text { Phosphatidal ethanolamine } \\
\text { ( } \mu \mathrm{g}) \\
\text { Sphingomyelin }(\mu \mathrm{g}) \\
\text { Polyglycerol phosphatide }(\mu \mathrm{g})\end{array}$ & $\begin{array}{l}1 \cdot 04 \\
198 \\
313 \\
125 \\
168 \\
94 \\
74 \\
84 \\
33 \\
51 \\
44 \\
17\end{array}$ & $\begin{array}{r}0 \cdot 02 \\
19 \cdot 75 \\
29 \cdot 33 \\
12 \cdot 04 \\
16 \cdot 35 \\
10 \cdot 00 \\
7 \cdot 27 \\
7 \cdot 82 \\
\\
3 \cdot 60 \\
\\
4 \cdot 95 \\
3.97 \\
1 \cdot 76\end{array}$ & $\begin{array}{r}0 \cdot 6-1 \cdot 42 \\
107-307 \\
173-537 \\
56-208 \\
93-299 \\
43-175 \\
34-125 \\
44-134 \\
16-56 \\
21-83 \\
25-75 \\
8-29\end{array}$ & $\begin{array}{r}39.9 \\
53.7 \\
30 \cdot 0 \\
23.6 \\
\\
26.8 \\
\\
10.5 \\
\\
16 \cdot 3 \\
14.1 \\
5.4\end{array}$ & $\begin{array}{c}32 \cdot 0-50 \cdot 8 \\
49 \cdot 6-57 \cdot 2 \\
20 \cdot 7-35 \cdot 1 \\
19 \cdot 7-30 \cdot 2 \\
\\
22 \cdot 7-30 \cdot 6 \\
7 \cdot 3-13 \cdot 9 \\
\\
11 \cdot 6-21 \cdot 9 \\
12 \cdot 1-15 \cdot 6 \\
4 \cdot 3-7 \cdot 4\end{array}$ \\
\hline
\end{tabular}

TABLE 3

FATTY AGID AND ALDEHYDE CONTENT IN THE CHOLINE AND ETHANOLAMINE PHOSPHATIDE FRAGTIONS OF SPERMATOZOA AND SEMINAL PLASMA FROM FOURTEEN BULLS

\begin{tabular}{|c|c|c|c|c|}
\hline \multirow[b]{2}{*}{$\begin{array}{l}\text { Fatty acid } \\
\text { or aldehyde }\end{array}$} & \multicolumn{2}{|c|}{ Spermatozoa } & \multicolumn{2}{|c|}{ Seminal plasma } \\
\hline & $\begin{array}{c}\text { Choline } \\
\text { phosphatide } \\
\text { (14)* }\end{array}$ & $\begin{array}{c}\text { Ethanolamine } \\
\text { phosphatide } \\
(5)^{*}\end{array}$ & $\begin{array}{c}\text { Choline } \\
\text { phosphatide } \\
\text { (1)* }\end{array}$ & $\begin{array}{c}\text { Ethanolamine } \\
\text { phosphatide } \\
(1)^{*}\end{array}$ \\
\hline $\begin{array}{l}10: 0 \\
12: 0 \\
14: 0 \text { DMA } \\
14: 0 \\
16: 0 \text { DMA } \\
16: 0 \\
16: 1 \\
18: 0 \\
18: 1 \\
18: 2 \\
20: 4 \\
22: 6\end{array}$ & $\begin{array}{r}3.5 \dagger \\
- \\
10.6 \\
3.6 \\
31.6 \\
11.8 \\
2.4 \\
4.2 \\
2.5 \\
0.9 \\
0.8 \\
28.2\end{array}$ & $\begin{array}{r}1.6 \\
0.1 \\
1.2 \\
1.6 \\
4.1 \\
48.5 \\
1.4 \\
10.4 \\
9.2 \\
14.3 \\
5.5 \\
2.0\end{array}$ & $\begin{array}{r}0.2 \\
0.2 \\
0.3 \\
3 \cdot 1 \\
23 \cdot 2 \\
19 \cdot 6 \\
0 \cdot 2 \\
25 \cdot 0 \\
13 \cdot 6 \\
8 \cdot 6 \\
0.3 \\
5.7\end{array}$ & $\begin{array}{c}1 \cdot 7 \\
- \\
\overrightarrow{1} \\
4 \cdot 0 \\
47 \cdot 6 \\
0.6 \\
16 \cdot 7 \\
12 \cdot 9 \\
14 \cdot 5 \\
0.6 \\
-\end{array}$ \\
\hline
\end{tabular}

* Numbers in parentheses represent number of chromatographed samples.

$\dagger$ Values are mean peak area as a percentage of the total peak area.

plasma from fourteen bulls are listed in Table 2. The total lipid was composed of $30.1 \%$ phospholipid and $19 \%$ cholesterol. The choline phosphatides accounted for $53.7 \%$ of the total phospholipid with the ethanolamine phosphatides, sphingomyelin and polyglycerol phosphatide making up 26.8, 14.1 
and $5.4 \%$, respectively. The plasmalogens constituted $39.9 \%$ of the phospholipid with the major component being phosphatidal choline.

\section{Fatty acids and aldehydes}

The relative percentages of the fatty acids and aldehydes are presented in Table 3.

Palmitic acid (16:0) was the most abundant saturated fatty acid in both phosphatide fractions of spermatozoa and in ethanolamine phosphatide of seminal plasma. In the choline phosphatide fraction of seminal plasma stearic acid (18:0) made up a higher percentage of the total fatty acids than palmitic acid.

The major unsaturated fatty acid in the choline phosphatide fractions of spermatozoa was docosahexaenoic acid (22:6), while in ethanolamine phosphatide fractions, linoleic acid $(18: 2)$ was the predominant unsaturate. Oleic acid was the predominant unsaturate in the choline phosphatide fraction of seminal plasma and linoleic acid (18:2) in the ethanolamine phosphatide fraction.

The choline phosphatide fractions of the spermatozoa from the two Guernsey bulls used in the study were completely devoid of caproic acid (10:0) and palmitoleic acid (16:1). No other differences between bulls or breeds were observed.

Palmitaldehyde (16:0 DMA) and myristaldehyde (14:0 DMA) were the only aldehydes detected in the choline and ethanolamine phosphatide fractions. Palmitaldehyde was the most abundant.

\section{DISGUSSION}

The quantity of total lipid per $10^{9}$ spermatozoa and per ml seminal plasma was lower than values reported by Komarek et al. (1964). This difference may have been due to differences in lipid extraction technique; however, in preliminary experiments, ultrasonic treatment using a Branson Model S-75 sonifier on spermatozoa before lipid extraction did not increase the quantity of lipid extracted from spermatozoa.

The relative amounts of phospholipid and cholesterol were similar to results of Miller (1960) and Komarek et al. (1964). Likewise, the percentage of cholesterol in seminal plasma lipid agreed with previous reports. However, we found the percentage phospholipid in seminal plasma lipid to be considerably less than reported by Komarek et al. (1964), i.e. 30.1\% compared to $68 \cdot 6 \%$. This difference may be explained by the fact that the quantitative methods employed in these two investigations differed considerably. In our study the cerebroside was excluded from quantitation with phospholipid since cerebroside does not contain phosphorus; conversely, the gravimetric procedure in their study would include cerebroside in the quantitation of phospholipid.

The relative proportions of choline phosphatides to ethanolamine phosphatides in the spermatozoal lipids were almost identical to that reported by Scott, Dawson \& Rowlands (1963) for rat spermatozoa recovered from the ductus deferens. Gray (1960b) reported the phosphatides of whole ram semen 
consisted of $72 \%$ lecithin, $24.8 \%$ cephalin and $3.2 \%$ sphingomyelin, which was similar to our findings. Lovern et al. (1957) reported that sphingomyelin constituted $5.5 \%$ of the total lipid of ram spermatozoa while we reported $9 \cdot 1 \%$ of the phospholipid for bull spermatozoa.

The finding that plasmalogen constituted an average of $35.2 \%$ of the total phospholipid of bull spermatozoa agreed with Masaki \& Hartree (1962) who found five samples of bull spermatozoa contained from 32 to $44 \%$ of the phospholipid in the form of plasmalogens. However, our results were lower than the 50 to $55 \%$ plasmalogen reported for ram spermatozoal phospholipid by Gray (1960b) and Hartree \& Mann (1961). Scott et al. (1963), on the other hand, reported that rat spermatozoal phospholipids contained only $20 \%$ plasmalogen.

The polyglycerol phosphatide was the smallest phospholipid fraction in the bull seminal plasma. This substance has previously been reported to be a constituent of ram spermatozoa by Hartree \& Mann (1961).

The fatty acid composition of the choline and ethanolamine phosphatides of bull spermatozoa and seminal plasma differed considerably from that reported previously for whole bull semen (Dietz, Pickett, Komarek \& Jensen, 1963), bull spermatozoa (Miller, 1960), the diglyceride fraction of bull semen (Terner \& Korsh, 1962) and the free fatty acids of ram spermatozoa (Hartree \& Mann, 1961). Analysis of choline plasmalogen and lecithin of ram semen by Gray (1960a) compared well with our fatty acid analysis. However, Gray (1960a) found considerable quantities of 15- and 17-carbon fatty acids which were not observed in our analysis, while we observed considerable quantities of docosahexaenoic acid $(22: 6)$ in the spermatozoal choline phosphatide fractions. Docosahexaenoic acid and other polyenoic acids have been found in lecithin fractions of mouse brown fat (Spencer \& Dempster, 1962) phosphatidyl ethanolamine fractions of human platelets (Marcus, Ullman, Safier \& Ballard, 1962), rabbit liver phospholipids (Moore \& Williams, 1963), ethanolamine, serine and choline phosphatides of human erythrocytes (Farquhar, 1962) and ox retina fatty acids (Hands, Sutherland \& Bartley, 1965). In most of these studies the presence of the polyenoic acids was attributed to the mitochondria of cells or tissues.

Richardson, Tappel, Smith \& Houle (1962) analysed heart and liver mitochondria of numerous species of fish and found that docosahexaenoic acid made up to $23.1 \%$ of the total fatty acid content in certain species. It thus seems highly probable that the mitochondrial helix of the sperm cell was the source of the docosahexaenoic acid found in the spermatozoal phospholipids.

Palmitaldehyde and myristaldehyde were the only two aldehydes identified in our study and the former was the most abundant in both phosphatide fractions. Insufficient quantities of phosphatide prevented more detailed analysis of the aldehyde constituents such as that performed by Gray (1960a) with choline plasmalogen of ram semen.

\section{ACKNOWLEDGMENTS}

Data presented are taken from a thesis presented by the senior author in partial fulfilment of the requirements for the Ph.D. degree, University of Minnesota. 
Gratitude is expressed for the financial aid and cooperation of Badger Breeders Cooperative, Shawano, Wisconsin; Consolidated Breeders Cooperative, Anoka, Minnesota; East Central Breeders Cooperative Association, Waupun, Wisconsin; Minnesota Valley Breeders Association, New Prague, Minnesota; and Tri-State Breeders Cooperative, Westby, Wisconsin.

\section{REFERENCES}

Bartlett, G. R. (1959) Phosphorus assay in column chromatography. F. biol. Chem. 234, 466.

Dietz, R. W., Pickett, B. W., Komarek, R. J. \& Jensen, R. G. (1963) Fatty acid composition of bovine semen. 7. Dairy Sci. 46, 468.

Farquhar, J. W. (1962) Human erythrocyte phosphoglycerides. I. Quantification of plasmalogens, fatty acids and fatty aldehydes. Biochim. biophys. Acta, 60, 80 .

Folch, J., Lees, M. \& Sloane-Stanley, G. H. (1957) A simple method for the isolation and purification of total lipids from animal tissues. 7 . biol. Chem. 226, 497.

GRAY, G. M. (1960a) The phospholipids of spleen with special reference to the fatty acid and fatty aldehyde compositions of the lecithin and kephalin fractions. Biochem. 7. 77, 82.

Gray, G. M. (1960b) The presence of lecithin in whole ram semen. Biochem. 7. 74, IP.

Hands, A. R., Sutherland, N. S. \& Bartley, W. (1965) Visual acuity of essential fatty acid-deficient rats. Biochem. 7. 94, 279.

Hartree, E. F. \& MANN, T. (1959) Plasmalogen in ram semen and its role in sperm metabolism. Biochem. 7. 71, 423.

Hartree, E. F. \& MANN, T. (1961) Phospholipids in ram semen: metabolism of plasmalogen and fatty acids. Biochem. F. 80, 464 .

Kölliker, R. A. von (1856) Physiologische Studien uber die Samenflussigkeit. Z. wiss. Zool. 7, 201.

Komarek, R. J., Pickett, B. W., Gibson, E. W. \& Jensen, R. G. (1965) Lipids of porcine spermatozoa, seminal plasma and gel. 7 . Reprod. Fert. 9, 131.

Komarek, R. J., Pickett, B. W., Gibson, E. W. \& Lanz, R. N. (1965) Composition of lipids in stallion semen. F. Reprod. Fert. 10, 337.

Komarek, R. J., Pickett, B. W., Lanz, R. N. \& Jensen, R. G. (1964) Lipid composition of bovine spermatozoa and seminal plasma. 7. Dairy Sci. 47, 531.

Lovern, J. A., Olley, J., Hartree, E. F. \& ManN, T. (1957) The lipids of ram spermatozoa. Biochem. f. 67,630 .

Marcus, A. J., Ullman, H. L., Safier, L. B. \& Ballard, H. S. (1962) Platelet phosphatides. Their fatty acid and aldehyde composition and activity in different clotting systems. F. clin. Invest. 41, 2198.

Masaki, J. \& Hartree, E. F. (1962) Distribution of metabolic activity, phospholipid and hyaluronidase between the heads and tails of bull spermatozoa. Biochem. F. 84, 347.

Massaro, E. J. (1962) A study of the mitochondrial phospholipids of human leukocytes. Ph.D. thesis, Univ. Texas (Libr. Congr. Card No. Mic. 63-5275).

Metcalfe, L. D. \& Schmitz, A. A. (1961) The rapid preparation of fatty acid esters for gas chromatographic analysis. Analyt. Chem. 33, 363.

MrLler, L. D. (1960) The lipids of bovine spermatozoa. Ph.D. thesis, Univ, Missouri (Libr. Congr. Card No. Mic. 60-4046).

Moore, J. H. \& Williams, D. L. (1963) The influence of dietary fat on the liver lipids of the rabbit. Can. F. Biochem. Physiol. 41, 1821.

Peifer, J. J. (1962) A rapid and simplified method of analysis by thin-layer chromatography using micro-chromatoplates. Mikrochim. Acta, 529.

Richardson, R., TAppel, A. L., Smith, L. M. \& Houle, C. R. (1962) Polyunsaturated fatty acids in mitochondria. F. Lipid Res. 3, 344.

Rouser, G., Bauman, A. J., Kritchevsky, G., Heller, D. J. \& O'Brien, J. S. (1961) Quantitative chromatographic fractionation of complex lipid mixture: brain lipids. F. Am. Oil Chem. Soc. $38,544$.

SAND, D. M. \& Schlenk, H. (1961) Acylated cyclodextrins as polar stationary phases for gas-liquid chromatography. Analyt. Chem. 33, 1642.

Scott, T. W., Dawson, R. M. C. \& Rowlands, I. W. (1963) Phospholipid interrelationships in rat epididymal tissue and spermatozoa. Biochem. $7.87,507$.

Spencer, W. A. \& Dempster, G. (1962) The lipids of mouse brown fat. Can. F. Biochem. Physiol. 40, 1705. 
TERner, G. \& Korsh, G. (1962) The biosynthesis of $\mathrm{G}^{14}$ labeled lipids by isolated bull spermatozoa. Biochemistry, 1, 367.

Wittenderg, J. B., KoreY, S. R. \& Swenson, F. H. (1956) The determination of higher fatty aldehydes in tissues. F. biol. Chem. 219, 39.

Zlatkis, A., ZaK, B. \& Boyle, J. (1953) A new method for the direct determination of serum cholesterol. 7. Lab. clin. Med. 41, 486. 